\title{
Heterologous Expression and Characterization of a Laccase from Laccaria bicolor in Pichia pastoris and Arabidopsis thaliana
}

\author{
Bo Wang ${ }^{1+}$, Ying $\mathrm{Yan}^{2+}$, Jing $\mathrm{Xu}^{1}$, Xiaoyan $\mathrm{Fu}^{1}$, Hongjuan Han ${ }^{1}$, Jianjie Gao ${ }^{1}$, Zhenjun $\mathrm{Li}^{1}$, Lijuan Wang ${ }^{1}$, \\ Yongsheng Tian ${ }^{1 *}$, Rihe Peng ${ }^{1 *}$, and Quanhong Yao ${ }^{1 *}$ \\ ${ }^{1}$ Shanghai Key Laboratory of Agricultural Genetics and Breeding, Agro-Biotechnology Research Institute, Shanghai Academy of Agricultural \\ Sciences, Shanghai 201106, P.R. China \\ ${ }^{2}$ Crop Breeding and Cultivation Research Institute, Shanghai Academy of Agricultural Sciences, Shanghai 201403, P.R. China
}

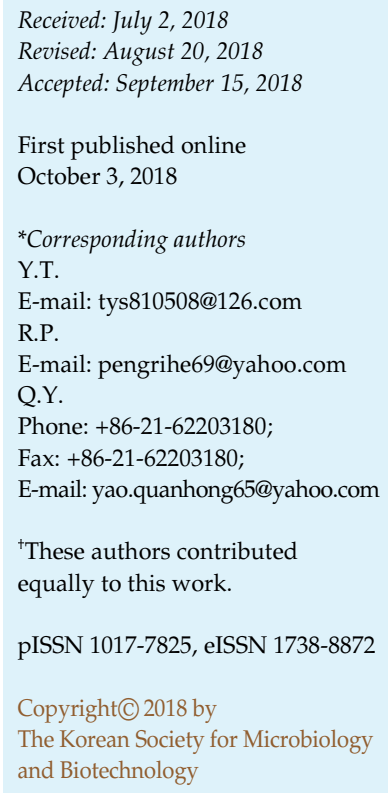

Laccases can oxidize a variety of phenolic and non-phenolic substrates including synthetic dyes. In this research, a laccase gene Lcc9 from Laccaria bicolor was chemically synthesized and optimized to heterogeneous expression in Pichia pastoris and Arabidopsis thaliana. The properties of recombinant laccase expressed by $P$. pastoris were investigated. The laccase activity was optimal at $3.6 \mathrm{pH}$ and $40^{\circ} \mathrm{C}$. It exhibited $K_{m}$ and $V_{\max }$ values of $0.565 \mathrm{mmol} \mathrm{l}^{-1}$ and $1.51 \mu \mathrm{mol} \mathrm{l}^{-1} \mathrm{~min}^{-1}$ for ABTS respectively. As compared with untransformed control plants, the laccase activity in crude extracts of transgenic lines exhibited a 5.4 to 12.4-fold increase. Both laccases expressed in transgenic P. pastoris or A. thaliana could decolorize crystal violet. These results indicated that $L$. bicolor laccase gene may be transgenically exploited in fungi or plants for dye decolorization.

Keywords: Laccase, Laccaria bicolor, heterologous expression, Pichia pastoris, Arabidopsis thaliana

\section{Introduction}

Laccases (E.C. 1.10.3.2) are oxygen oxidoreductases belonging to the blue multicopper oxidase family, which also includes ferroxidases, ascorbate oxidases and ceruloplasmins. Laccase was first found in latex obtained from the tree Rhus vernicifera by Yoshida. In 1894, the enzymes were isolated and purified from lacquer trees of Southeast Asia by Bertrand [1]. Laccase is widely distributed in plants, bacteria, fungi and insects. Among them, fungal laccase has been the most widely studied. In 1986, the presence of laccase was observed in fungi for the first time [2]. So far, a large number of fungi have been confirmed as producers of laccases, especially Basidiomycetes and Ascomycetes fungi. Four acidic laccase isoforms have been detected in Ganoderma lucidum BEOFB 431 [3], and recently, an extracellular laccase $(\mathrm{LccH})$ from the newlyisolated Basidiomycetous fungus Hexagonia hirta MSF2 was also reported [4].

Laccases catalyze the oxidation of a wide variety of phenolic and non-phenolic compounds using molecular oxygen as the sole electron acceptor and generate water as the by-product. During wheat straw fermentation, laccases were also the dominant ligninolytic enzymes in some fungal species [5]. Tetracycline can be degraded by immobilized laccase and the mechanism was proposed [6]. Synthetic dyes were also decolorized by laccases from different organisms $[7,8]$. The scope of laccase substrates can be widened to higher-redox potential compounds than laccase itself with the help of diffusible electron carriers like 2,2'-azino-bis(3-ethylbenzothiazoline-6-sulphonic) (ABTS) that constitute the laccase-mediator system (LMS) [9]. 
Thus, laccase and LMS have been found to have potential applications in bioremediation, biofuel cells, biosensors, textiles, pulp and paper, and food and organic synthesis. Interest in the bioremediation of laccases has increased recently because of their potential use in the detoxification of pollutants and in bioremediation of phenolic compounds [10]. Discovery and characterization of novel laccases are still important for industrial application.

Laccaria bicolor is a ubiquitous, ectomycorrhizal symbiotic fungus of hardwood and conifer roots found in different ecological niches. The genome sequence of L. bicolor has been reported and the 65-megabase genome contains $\sim 20,000$ predicted protein-encoding genes [11]. There have been 11 multi-copper oxidase genes of L. bicolor divided into two distinct subfamilies to laccases sensu stricto (lcc1 to $l c c 9)$ and ferroxidases (lcc10 and lcc11). Transcript profiling using whole-genome expression arrays and quantitative reverse transcriptase-polymerase chain reaction has revealed a specific function of these enzymes [12]. We have heterologous expression and characterization of one laccase (LbLCC3) from L. bicolor. But the function and properties of the other laccases from L. bicolor are still unclear. In this study, we synthesized a gene according to the amino acid sequence of LbLCC9, and transferred this gene into $P$. pastoris and A. thaliana. The characteristics of the recombinant laccase from $P$. pastoris were investigated and the dye decolorization ability of both laccases expressed in transgenic $P$. pastoris and A. thaliana were verified.

\section{Materials and Methods}

\section{Organisms, Reagents and Plant Growth Conditions}

The Escherichia coli strain DH5 $\alpha$ (Invitrogen, USA) was applied to DNA and plasmid manipulations. P. pastoris strain GS115 (Invitrogen, USA) was used for heterologous expression of the laccase. pMD18-T (TaKaRa, China) and modified pPIC9K vectors (our lab) were used as cloning and expression vector respectively. All enzymes of DNA manipulation were purchased from TaKaRa (China). Bradford protein quantitative test kit was purchased from Shanghai Generay Biotech Co., Ltd. ABTS (2-2'-azino-bis-3ethylbenzothiazoline-6-sulfonate) and crystal violet (hexamethylpararosaniline chloride) were obtained from Shanghai Sangon Co. Ltd. (China). Unless otherwise stated, all other chemicals were obtained from commercial sources and of analytical grade. The media used for the expression of recombinant protein were prepared following the Multi-Copy Pichia Expression Kit (Invitrogen, USA). Agrobacterium tumefaciens GV3101 and A. thaliana (ecotype Columbia L) plants were sourced from our laboratory. Seeds of $A$. thaliana were surface sterilized with bleaching powder $(5 \%, \mathrm{w} / \mathrm{v})$ for $20 \mathrm{~min}$, washed with sterile water three times, placed in Petri dishes that contained Murashige and Skoog medium with $0.8 \%$ agar, and then placed in the dark at $4{ }^{\circ} \mathrm{C}$ for 3 days. All of the plants were cultivated in a growth room at $22^{\circ} \mathrm{C}$ under standard long-day conditions (16:8 h day-night cycle, $\sim 120 \mu \mathrm{M}$ photons $\mathrm{m}^{-2} \mathrm{~s}^{-1}$ light intensity).

\section{Synthesis, Cloning and Vector Construction}

According to the amino acids sequence of LbLCC9 (GenBank: ACN49096.1), LbLCC9I was designed and synthesized according to preferential codon usage in yeast. The synthetic gene was cloned into the pMD18-T vector and sequenced. The amino acid sequences used for analysis were retrieved from the database of the National Center for Biotechnology Information (http://www. ncbi.nlm.nih.gov/) and protein domain was conducted using NCBI conserved domain database (http://www.ncbi.nlm.nih.gov/ Structure/cdd/cdd.shtml). The DNA fragment of LbLCC9I gene was subcloned into a modified pPIC9K vector and pCAMBIA1301 vector.

\section{Transformation, Screening and Expression of LbLCC9I in P. pastoris}

The expression vector pPIC9K/LbLCC9I was transformed into E. coli DH5 $\alpha$ and extracted according to the standard method. Ten microliters of plasmid was digested into two fragments with restriction enzyme $B g l \mathrm{II}$, and then transformed into P. pastoris GS115 competent cells by electroporation (Bio-Rad Genepulser, USA). After being pulsed, P. pastoris cells were spread on selective RDB plates and incubated at $28^{\circ} \mathrm{C}$ until colonies appeared, and these were picked and streaked on BMMY plates containing ABTS. If the LbLCC9I gene is recombined into yeast genome DNA and expressed successfully, the medium around the yeast colony should turn blue. Therefore, a blue colony was selected and further confirmed by PCR.

A single colony was picked and inoculated in $50 \mathrm{ml}$ of BMGY medium at $28^{\circ} \mathrm{C}$ in a shaking incubator until the culture reached to $\mathrm{OD}_{600}=2-6$. The cells were harvested by centrifuging and resuspended in $100 \mathrm{ml}$ of BMMY medium supplemented and returned to an incubator to grow for 3 days. Methanol was added to a final concentration of $1 \%$ every $24 \mathrm{~h}$.

\section{Purification and Characterization of Recombinant Laccase in P. pastoris}

The crude enzyme in the supernatant of methanol-induced culture was precipitated by $40 \%$ and $70 \%$ ammonium sulfate. PBS (pH 6.0) was used to dissolve and dialysis the precipitation. Then the desalted solution was purified by nickel-charged iminodiacetic acid column according to the operation manual. The molecular mass of the laccase was estimated by SDS-PAGE with a $12 \%$ polyacrylamide gel. The concentration of purified protein was quantified by Bradford Protein Assay with bovine serum albumin as a standard. The activity measurement was performed with $0.5 \mathrm{mM}$ ABTS in $0.2 \mathrm{M}$ citrate-phosphate buffer at $37^{\circ} \mathrm{C}$ in a total of $200 \mu \mathrm{l}$. The assay mixture was incubated at $37^{\circ} \mathrm{C}$ for $10 \mathrm{~min}$ 
before the enzyme was added. The reaction was terminated by addition of $\mathrm{NaN}_{3}$ after $120 \mathrm{~min}$. The absorbance of reactant was measured at $420 \mathrm{~nm}\left(\varepsilon=12,000 \mathrm{M}^{-1} \mathrm{~cm}^{-1}\right)$. One unit (U) of laccase activity was defined as the amount of enzyme catalyzing the formation of $1.0 \mu \mathrm{mol}$ of product per minute under the assay conditions. The optimal $\mathrm{pH}$ and temperature, stability at different $\mathrm{pH}$ and temperature were determined. $K_{m}$ and $V_{\max }$ were assayed using ABTS from 0.025 to $1.5 \mathrm{mM}$. Kinetic parameters were determined using Lineweaver-Burk plots. There were three replicates of each treatment.

\section{Transformation of the LbLCC9I Gene into A. thaliana}

The vector pCAMBIA1301/LbLCC9I was introduced into the A. tumefaciens GV3101 by electroporation and subsequently used to transform $A$. thaliana by a previously described floral dip method to generate transgenic plants [13]. Transgenic plants were obtained from plants grown on a medium containing $40 \mathrm{mg}$ hygromycin $\mathrm{l}^{-1}$. Genomic DNA extracted from $A$. thaliana seedlings was used for PCR to confirm the transfection of a foreign gene. The actin2 gene of A. thaliana (ACT2, GenBank Accessin No. U41998) was used as a reference. PCR reactions were carried out in 30 cycles lasting $30 \mathrm{sec}$ at $94^{\circ} \mathrm{C}, 30 \mathrm{sec}$ at $55^{\circ} \mathrm{C}, 30 \mathrm{sec}$ at $72^{\circ} \mathrm{C}$, with a final extension at $72^{\circ} \mathrm{C}$ for $10 \mathrm{~min}$ with the following primers: ACT2 (ACT2F: 5'-AGTAAGGTCACGTCCAGCAAGG-3'; ACT2R: 5'-GCACCCTGTTCTTCTTACCGAG-3') and LbLCC9I (LbLCC9IF: 5'-ACCATTGTAGGTTGGACACAG-3'; LbLCC9IR: 5'-ATTGGT GGTCCACATCCACTG-3'). The PCR products were separated on $1 \%(\mathrm{w} / \mathrm{v})$ agarose gels.

\section{Expression of the LbLCC9I Gene in Transgenic A. thaliana}

The 3-week-old transgenic and wild-type (WT) seedlings were used to extract total RNA according to the manufacturer's instructions of the Multisource Total RNA Miniprep Kit (Axygen, USA). A reverse transcription system was conducted with $5 \mu \mathrm{g}$ of total RNA as the template (Promega, USA), and the products were qualitatively amplified by RT-PCR. PCR and electrophoretic procedures are the same as described above.

Similar 3-week-old seedlings were used to extract crude protein. Transgenic and WT plants were ground in liquid nitrogen in a mortar with pestle and homogenized with a $0.2 \mathrm{M}$ citratephosphate buffer ( $\mathrm{pH}$ 3.6). Plant tissue was suspended in this buffer according to $100 \mathrm{mg} / \mathrm{ml}$. The homogenate was centrifuged at $12,000 \times g\left(4^{\circ} \mathrm{C}\right)$. The supernatant was used to detect the laccase activity (added ABTS to $0.2 \mathrm{mM}$ ). Native-PAGE was performed according to the reported method [14].

Heterologous Expression of Laccases in P. pastoris and A. thaliana for Decolorization of Crystal Violet

The decolorization of crystal violet was assessed using freshly prepared enzyme from $P$. pastoris and the extract crude protein from Arabidopsis. The reaction mixture for the decolorization assay contained $0.1 \mathrm{mM}$ of crystal violet, Mcllvaine buffer and $50 \mu \mathrm{l}$ of the above enzyme in a total of $200 \mu \mathrm{l}$. ABTS, as the mediator, was added if necessary. Reaction was initiated by adding enzyme to the assay mixtures and then subsequently incubated in dark for $24 \mathrm{~h}$. The amount of dye was determined by measuring the absorbance at $590 \mathrm{~nm}$ and calculated from standard curves of absorbance versus dye concentration.

\section{Results and Discussion}

\section{Synthesis of LbLCC9I and Genetic Transformation of P. pastoris}

Amino acid sequence analysis showed $56.1 \%$ homology between LbLCC9 and a laccase (PDB accession: 1HFU) from Coprinopsis cinerea. LbLCC9I had the fungal laccase signature sequences L1-L4 [15]. Three cupredoxin-like domains corresponding to the laccase from Trametes versicolor were predicted. In the phylogenetic analysis of basidiomycete laccases sensu stricto, Lcc9 and four other laccases from $L$. bicolor were clustered with members of the large C. cinerea laccase family [12]. To improve the expression in yeast, the sequence of $L b L C C 9$ was modified, synthesized and renamed LbLCC9I. The nucleotide sequences of LbLCC9I and LbLCC 9 were $78.23 \%$ identical. The DNA fragment was inserted into pPIC9K to construct expression vector after PCR amplification. Linearized expression vector was transformed into $P$. pastoris by electroporation. The transformants confirmed by PCR were chosen for further investigation.

\section{Characterization of LbLCC9I Expressed by $P$. pastoris}

After three consecutive days of fermentation, the enzyme LbLCC9I was purified by affinity chromatography with Ni-column. The purified laccase appeared as a single protein band on SDS-PAGE gel and the molecular mass of the purified laccase was consistent with its theoretical molecular weight (Fig. 1). This is similar to another laccase in L. bicolor as we reported earlier, the molecular mass of that laccase is $56 \mathrm{kDa}$ [16]. The normal laccase enzymes have molecular weight ranging from 50 to $130 \mathrm{kDa}$ [17]. Difference between the molecular weight predicted from the peptide sequence and the experimentally obtained molecular weight is caused by glycosylation, which typically accounts for about $10-20 \%$ of the total MW [18]. The C. cinereus laccase CCLCC5I purified from yeast can be glycosylated, as proved by the treatment of deglycosylation enzyme Endo H [19].

Gallic acid, tannic acid, syringaldazine, guaiacol and ABTS have been used as laccase indicators for the detection 


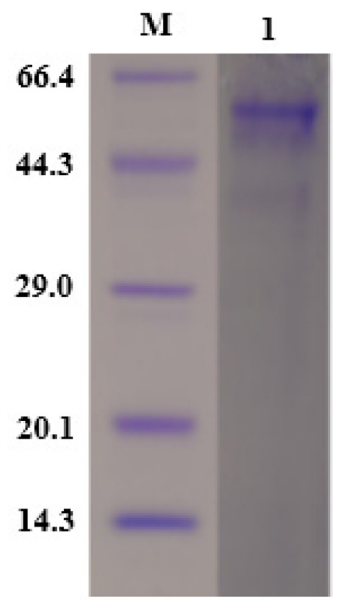

Fig. 1. SDS-PAGE of recombinant LbLCC9I expressed via P. pichia.

The gel was stained with Coomassie brilliant blue. Lanes M, molecular weight marker, Lane 1, purified LbLCC9I.

of laccase producers. They can be oxidized by laccases to produce a color. ABTS is one of the most common and electron substrates used for the measurement of laccase activity and the definition of the international unit of laccase activity is based on ABTS oxidation [20]. With ABTS as a substrate, the $K m$ and Vmax values of the heterologous laccase were $0.565 \mathrm{mM}$ and $1.51 \mu \mathrm{M} \mathrm{min}^{-1}$ respectively at $\mathrm{pH} 3.6$ and $40^{\circ} \mathrm{C}$. The $\mathrm{Km}$ values for a large number of laccases have been described. This parameter has great variance depending on the enzyme source and the substrates [18]. The Km of LbLCC9I is slightly higher than that of LbLCC3I from the same organism [16].

Using ABTS as a substrate, the optimum $\mathrm{pH}$ value of catalytic reaction by LbLCC9I was 3.6, which was similar to the laccases from Trametes modesta [21], Panus rudis [22], and Albatrella dispansus [23]. Moreover, the activity of LbLCC9I was only $46.2 \%$ and $38.5 \%$ when the catalytic reaction was carried out at $\mathrm{pH} 2.2$ and $\mathrm{pH} 5.0$ respectively. It became completely inactive at pH 5.6-7.0 (Fig. 2). The stability of the enzyme also decreased with the increase of $\mathrm{pH}$ values. The decrease of laccase activity in neutral or alkaline $\mathrm{pH}$ may be because of the inhibition by hydroxide anion. After incubation at $4^{\circ} \mathrm{C}$ for $24 \mathrm{~h}$, the residual activity was $61.3 \%$ at $\mathrm{pH} 5.0$. The enzyme was stable at acidic $\mathrm{pH}$ (Fig. 2). This was consistent with the optimum $\mathrm{pH}$ and probably indicated the laccase function under acidic physiological conditions.

The optimum reaction temperature and thermal stability of LbLCC9I were determined with ABTS as the substrate at $\mathrm{pH}$ 3.6. The laccase had maximum activity at $40^{\circ} \mathrm{C}$ (Fig. 3).

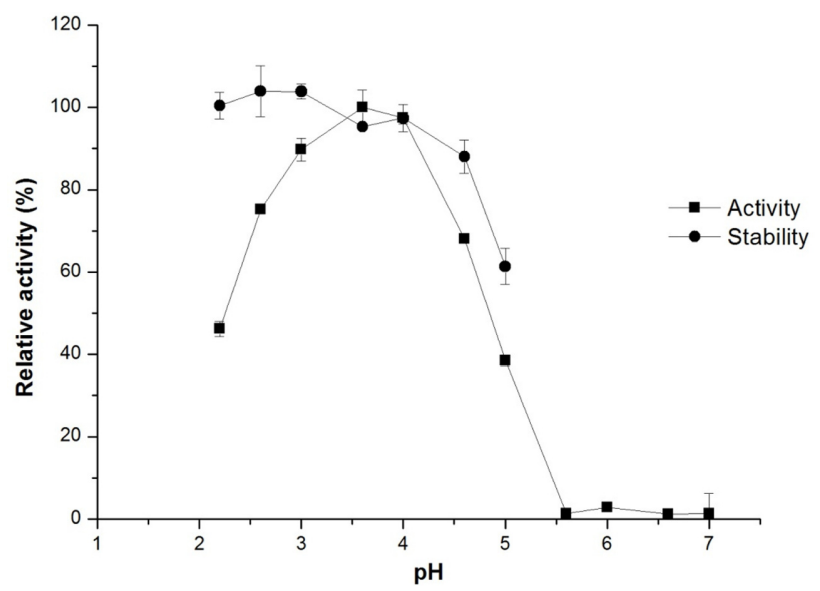

Fig. 2. Effects of $\mathrm{pH}$ on laccase activity and stability. The optimum $\mathrm{pH}$ was determined spectrophotometrically with ABTS in $0.2 \mathrm{M}$ citrate-phosphate buffer $(\mathrm{pH} 2.2-7.0)$ at $37^{\circ} \mathrm{C}$. The stability of LbLCC9I was done by enzyme incubation at $4^{\circ} \mathrm{C}$ in various $\mathrm{pH}$ buffers for $24 \mathrm{~h}$. Enzyme activity at starting time was assumed as $100 \%$ stability. Enzyme assays were performed in triplicates.

The enzyme retained most activity at $20-40^{\circ} \mathrm{C}$ after $60 \mathrm{~min}$ (Fig. 4). It was not stable at higher temperatures than $60^{\circ} \mathrm{C}$ during prolonged incubation. The residual activities were reduced to $7.4 \%$ and $4.3 \%$ after incubation at 60 and $70^{\circ} \mathrm{C}$ for $60 \mathrm{~min}$, respectively. The optimum temperature for laccases is generally between $30^{\circ} \mathrm{C}$ and $50^{\circ} \mathrm{C}$ [24]. But the optimum temperature of a novel laccase from the thermophilic ascomycete fungus Scytalidium thermophilum was $80^{\circ} \mathrm{C}$ using DMP as a substrate [14].

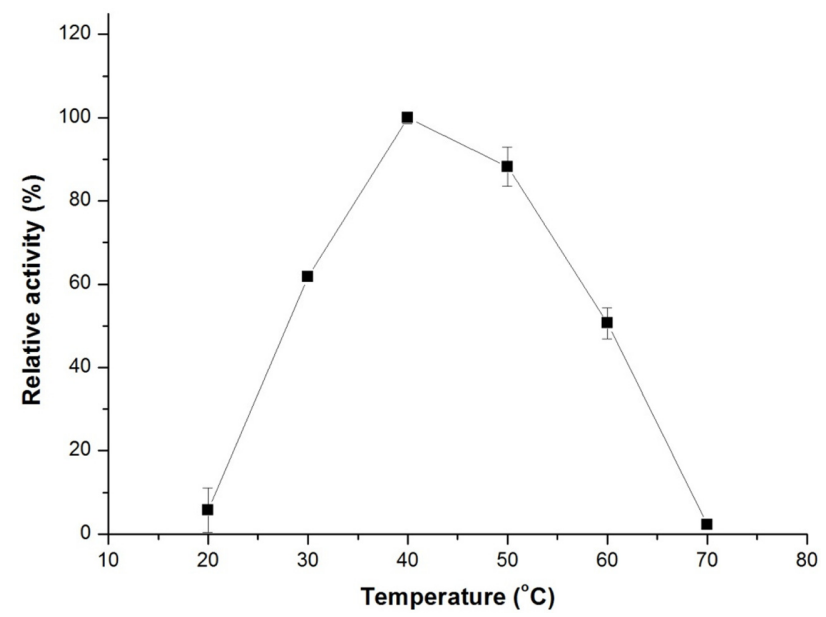

Fig. 3. Effects of temperature on laccase activity. The laccase activity was determined spectrophotometrically with ABTS in $0.2 \mathrm{M}$ citrate-phosphate buffer ( $\mathrm{pH}$ 3.6) at different temperatures $\left(20-70^{\circ} \mathrm{C}\right)$ for $2 \mathrm{~h}$. Enzyme assays were performed in triplicates. 


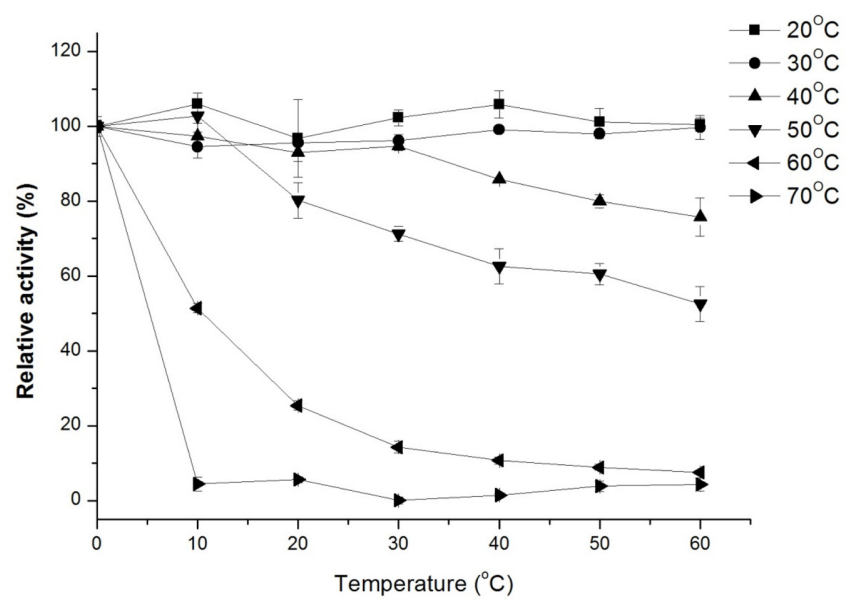

Fig. 4. Effects of temperature on laccase stability.

The enzyme stability was checked by enzyme incubation at various temperatures $\left(20-70^{\circ} \mathrm{C}\right)$ with different durations (10 min increments). Enzyme activity at start of incubation time was assumed as $100 \%$ stability. Enzyme assays were performed in triplicates.

\section{Transformation and Expression of the LbLCC9I Gene in} Arabidopsis

The LbLCC9I gene was transformed into $A$. thaliana by an A. tumefaciens (GV3101)-mediated transformation and verified through PCR (Fig. 5A). Genomic DNA extracted from $A$. thaliana seedlings was used for PCR to confirm the insertion of a foreign gene. After segregation analyses, three $\mathrm{T}_{2}$ lines were selected for further analysis. Wild-type plants were also grown to be used as controls. Expressions of the LbLCC9I gene were determined from $\mathrm{T}_{2}$ plants by using RT-PCR. The specific DNA fragment (300 bp) of LbLCC9I was amplified from three transgenic lines. However, no signals were detected in wild-type plants (Fig. 5B). Reverse transcriptase PCR demonstrated that the LbLCC9I gene was successfully transcribed in the transgenic plants. As compared with untransformed control plants, the laccase activity in crude extracts of transgenic plants 97-17, 97-19 and 97-21 exhibited a 5.4 to 12.4 -fold increase (Fig. 6). This indicates the transgenic Arabidopsis could express active laccase from L. bicolor.

Laccases were encoded by multigene families in plants and $A$. thaliana contained 17 laccases with different physiological functions including lignin synthesis [25]. A laccase gene lac3 from poplar was essential for normal cell wall structure and integrity in xylem fibers [26]. Reduced expression of another laccase of Populus deltoids resulted in transgenic plants with changes in syringyl/guaiacy ratios as well as altered sugar release phenotypes [27]. Two laccase genes of carrot had different responses to abiotic
A WT $97-8$ 97-17 97-1897-19 97-21

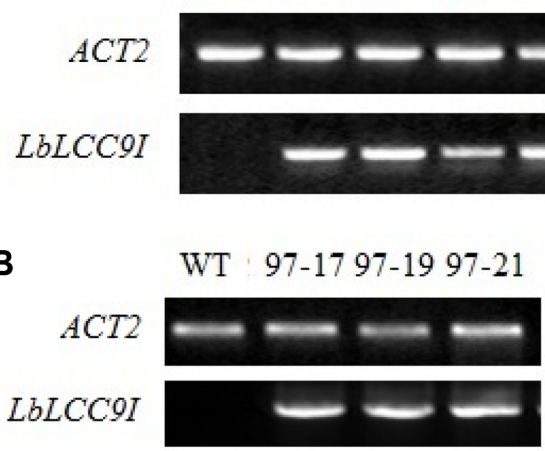

Fig. 5. The recombination and transcription of LbLCC9I in transgenic lines (97-17, 97-19 and 97-21) were confirmed by PCR (A) and RT-PCR (B).

The A. thaliana actin2 gene was used as the control to show the normalization of the amount of template in PCR.

and metal ion stresses [28]. But in this study, all the transgenic lines were phenotypically indistinguishable from the wild-type line when they were grown on MS agar plates. This indicates that the insertion of the LbLCC9I gene in these plants produced no visible morphological changes.

\section{Decolorization by Recombinant Laccases from $P$. pastoris and A. thaliana}

Triphenylmethane dyes were employed in several industrial dyeing processes, but they are toxic, mutagenic and carcinogenic in mammalian cells. Study about the biodegradation of these dyes helps to eliminate the threat to humans. So the decolorization ability of laccases expressed in P. pastoris and transgenic Arabidopsis on crystal violet were investigated. ABTS is necessary for the decolorization of crystal violet by the two laccases. A similar result could be found in a heterologous laccase from Colletotrichum lagenarium [29]. In the presence of ABTS, the decolorization rates of crystal violet by laccases in P.pastoris or A.thaliana reached $90.7 \%$ and $83.6 \%$, respectively (Fig. 7). Expression of LbLCC9I gene in $P$. pastoris was helpful for production of this laccase to meet the requirements of industrial applications. Phytoremediation was a low-cost method for removal of various organic pollutants. The application of laccase in pollution remediation has attracted many researchers. Transgenic A.thaliana overexpressing a laccase gene from cotton exhibited enhanced resistance to 2,4,6-trichlorophenol [23]. The laccase of Coriolus versicolor was introduced into tobacco plants and one transgenic plant was able to remove bisphenol A and pentachlorophenol [30]. Crystal violet was 
A

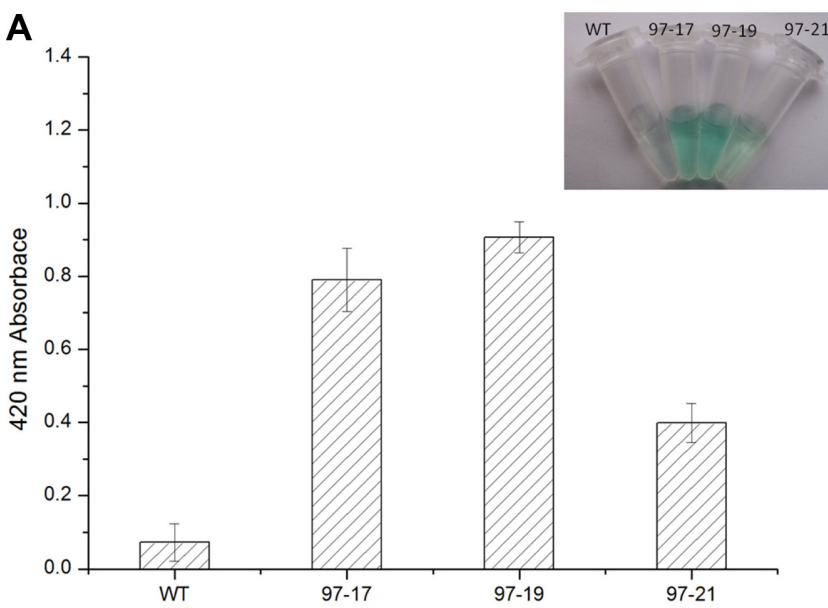

B

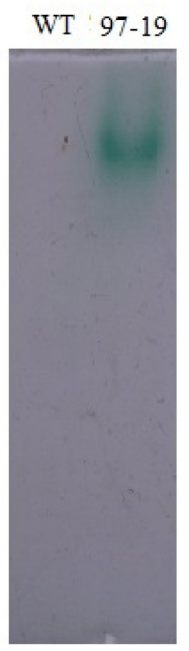

Fig. 6. The laccase activity in crude protein extracts of transgenic and wild-type (WT) plants.

(A) The transgenic and WT plants (fresh weight $100 \mathrm{mg}$ ) were ground in liquid nitrogen in a mortar with pestle and homogenized with $1 \mathrm{ml}$ $0.2 \mathrm{M}$ citrate-phosphate buffer ( $\mathrm{pH}$ 3.6). The homogenate was centrifuged and the supernatant was used as crude extracts. Adding ABTS to $0.2 \mathrm{mM}$, the reactions were done at $37^{\circ} \mathrm{C}$ for $1 \mathrm{~h}$. (B) NativePAGE of crude protein extracts of transgenic line (97-19) and wildtype plants (WT).

converted to non-toxic leucocrystal violet by transgenic Arabidopsis expressing a Citrobacter sp. triphenylmethane reductase [31]. In this study, the transgenic Arabidopsis could express a fungal laccase from L. bicolor and this laccase could effectively decolorize crystal violet. These results indicated that fungal laccase genes may be transgenically exploited into plants for bioremediation. Our report provided an alternative approach to dye decolorization in the environment.

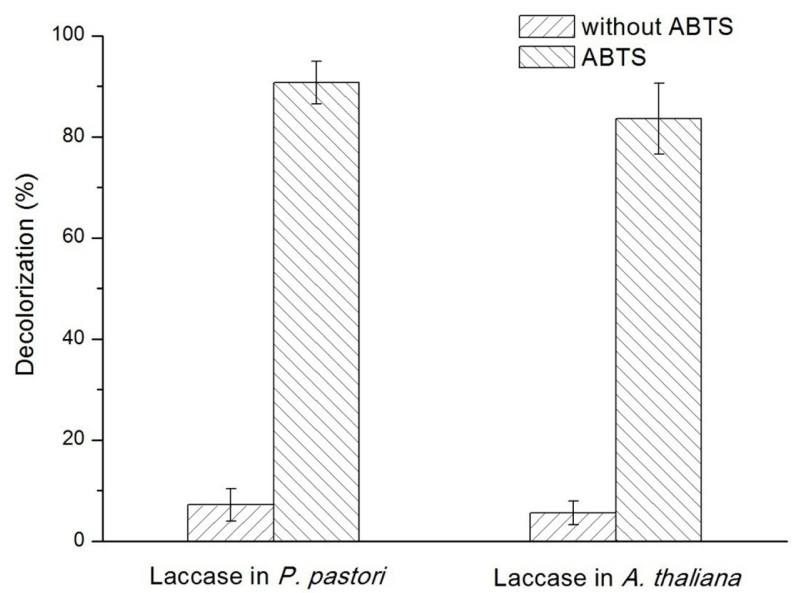

Fig. 7. Decolorization of crystal violet by laccases expressed in P. pastoris and transgenic Arabidopsis.

Decolorization was detected with or without $0.1 \mathrm{mmol} \mathrm{l}^{-1}$ ABTS as a mediator by different laccases.

\section{Acknowledgements}

The research was supported by the Key Project Fund of the Shanghai Municipal Committee of Agriculture (gongzi2014 7-1-3, zhongzi 2016 1-2, chuangzi 2018 1-5), Shanghai Natural Science Foundation (18ZR1413100) and National Natural Science Foundation (31672439). The "Pan-Gao" plan of Shanghai Academy of Agricultural Science (PG212) The Youth Talent Development Plan of Shanghai Municipal Agricultural System (2016 1-30 and 2018 1-31).

\section{Conflict of Interest}

The authors have no financial conflicts of interest to declare.

\section{References}

1. Rivera-Hoyos CM, Morales-Álvarez ED, Poutou-Piñales RA, Pedroza-Rodríguez AM, Rodríguez-Vázquez R, DelgadoBoada JM. 2013. Fungal laccases. Fungal Biol. Rev. 27: 67-82.

2. Upadhyay P, Shrivastava R, Agrawal PK. 2016. Bioprospecting and biotechnological applications of fungal laccase. 3 Biotech. 6: 15.

3. Ćilerdžić J, Stajić M, Vukojević J, Lončar N. 2014. Intraspecific diversity in the production and characterization of laccase within Ganoderma lucidum. Bioresouces 9: 5577-5587.

4. Kandasamy S, Muniraj IK, Purushothaman N, Sekar A, Sharmila DJ, Kumarasamy R, et al. 2016. High level secretion of laccase $(\mathrm{LccH})$ from a newly isolated white-rot 
basidiomycete, Hexagonia hirta MSF2. Front Microbiol. 7: 707.

5. Cilerdzic J, Galic M, Vukojevic J, Brceski I, Stajic M. 2017. Potential of selected fungal species to degrade wheat straw, the most abundant plant raw material in europe. BMC Plant Biol. 17: 249.

6. Yang J, Lin $Y$, Yang X, Ng TB, Ye X, Lin J. 2017. Degradation of tetracycline by immobilized laccase and the proposed transformation pathway. J. Hazard Mater. 322: 525-531.

7. Wang S-S, Ning Y-J, Wang S-N, Zhang J, Zhang G-Q, Chen Q-J. 2017. Purification, characterization, and cloning of an extracellular laccase with potent dye decolorizing ability from white rot fungus Cerrena unicolor GSM-01. Int. J. Biol. Macromol. 95: 920-927.

8. Zhuo R, Yuan P, Yang Y, Zhang S, Ma F, Zhang X. 2017. Induction of laccase by metal ions and aromatic compounds in Pleurotus ostreatus HAUCC 162 and decolorization of different synthetic dyes by the extracellular laccase. Biochem. Eng. J. 117: 62-72.

9. Mate DM, Alcalde M. 2017. Laccase: a multi-purpose biocatalyst at the forefront of biotechnology. Microb. Biotechnol. 10: 1457-1467.

10. Ba S, Vinoth Kumar V. 2017. Recent developments in the use of tyrosinase and laccase in environmental applications. Crit. Rev. Biotechnol. 37: 819-832.

11. Martin F, Aerts A, Ahren D, Brun A, Danchin EG, Duchaussoy $F$, et al. 2008. The genome of Laccaria bicolor provides insights into mycorrhizal symbiosis. Nature 452: 88-92.

12. Courty PE, Hoegger PJ, Kilaru S, Kohler A, Buee M, Garbaye J, et al. 2009. Phylogenetic analysis, genomic organization, and expression analysis of multi-copper oxidases in the ectomycorrhizal basidiomycete Laccaria bicolor. New Phytol. 182: 736-750.

13. Xu J, Tian YS, Peng RH, Zhu B, Gao JJ, Yao QH. 2012. Characterization of a thermostable beta-glucuronidase from Thermotoga maritima expressed in Arabidopsis thaliana. Appl. Microbiol. Biotechnol. 95: 1211-1219.

14. Ben Younes S, Sayadi S. 2011. Purification and characterization of a novel trimeric and thermotolerant laccase produced from the ascomycete Scytalidium thermophilum strain. J. Mol Catal. B: Enzymatic 73: 35-42.

15. Kumar SV, Phale PS, Durani S, Wangikar PP. 2003. Combined sequence and structure analysis of the fungal laccase family. Biotechnol. Bioeng. 83: 386-394.

16. Wang B, Wang X, Tian Y, Li Z, Gao J, Yan Y, et al. 2015. Heterologous expression and characterization of a laccase from Laccaria bicolor in Pichia pastoris. Biotechnol. Biotechnol. Equip. 30: 63-68.

17. Senthivelan T, Kanagaraj J, Panda RC. 2016. Recent trends in fungal laccase for various industrial applications: an ecofriendly approach - a review. Biotechnol. Bioprocess Eng. 21: 19-38.

18. Viswanath B, Rajesh B, Janardhan A, Kumar AP, Narasimha G. 2014. Fungal laccases and their applications in bioremediation.
Enzyme Res. 2014: 163242

19. Lin Y, Zhang Z, Tian Y, Zhao W, Zhu B, Xu Z, et al. 2013. Purification and characterization of a novel laccase from Coprinus cinereus and decolorization of different chemically dyes. Mol. Biol. Rep. 40: 1487-1494.

20. Forootanfar H, Faramarzi MA. 2015. Insights into laccase producing organisms, fermentation states, purification strategies, and biotechnological applications. Biotechnol. Pro. 31: 1443-1463.

21. Nyanhongo GS, Gomes J, Gübitz GM, Zvauya R, Read J, Steiner W. 2002. Decolorization of textile dyes by laccases from a newly isolated strain of Trametes modesta. Water Res. 36: 1449-1456.

22. Zhang M, Wu F, Wei Z, Xiao Y, Gong W. 2006. Characterization and decolorization ability of a laccase from Panus rudis. Enzyme Microb. Technol. 39: 92-97.

23. Wang GD, Li QJ, Luo B, Chen XY. 2004. Ex planta phytoremediation of trichlorophenol and phenolic allelochemicals via an engineered secretory laccase. Nat. Biotechnol. 22: 893-897.

24. Abd El Monssef RA, Hassan EA, Ramadan EM. 2016. Production of laccase enzyme for their potential application to decolorize fungal pigments on aging paper and parchment. Ann. Agric. Sci. 61: 145-154.

25. Turlapati PV, Kim KW, Davin LB, Lewis NG. 2011. The laccase multigene family in Arabidopsis thaliana: towards addressing the mystery of their gene function(s). Planta 233: 439-470.

26. Ranocha P, Chabannes M, Chamayou S, Danoun S, Jauneau A, Boudet AM, et al. 2002. Laccase down-regulation causes alterations in phenolic metabolism and cell wall structure in poplar. Plant Physiol. 129: 145-155.

27. Bryan AC, Jawdy S, Gunter L, Gjersing E, Sykes R, Hinchee MA, et al. 2016. Knockdown of a laccase in Populus deltoides confers altered cell wall chemistry and increased sugar release. Plant Biotechnol. J. 14: 2010-2020.

28. Ma J, Xu ZS, Wang F, Xiong AS. 2015. Isolation, purification and characterization of two laccases from Carrot (Daucus carota L.) and their response to abiotic and metal ions stresses. Protein J. 34: 444-452.

29. Wang B, Yan Y, Tian Y, Zhao W, Li Z, Gao J, et al. 2016. Heterologous expression and characterisation of a laccase from Colletotrichum lagenarium and decolourisation of different synthetic dyes. World J. Mmicrobiol. Biotechnol. 32: 40.

30. Sonoki T, Kajita S, Ikeda S, Uesugi M, Tatsumi K, Katayama $\mathrm{Y}$, et al. 2005. Transgenic tobacco expressing fungal laccase promotes the detoxification of environmental pollutants. Appl. Microbiol. Biotechnol. 67: 138-142.

31. Fu XY, Zhao W, Xiong AS, Tian YS, Zhu B, Peng RH, et al. 2013. Phytoremediation of triphenylmethane dyes by overexpressing a Citrobacter sp. triphenylmethane reductase in transgenic Arabidopsis. Appl. Microbiol. Biotechnol. 97: 1799-1806. 